\title{
Increasing the functional quality of Crocus sativus L. by-product (tepals) by controlling spectral composition
}

\author{
Matteo Orlando ${ }^{1} \cdot$ Alice Trivellini $^{1}$ (D) Martina Puccinelli ${ }^{2} \cdot$ Antonio Ferrante $^{3} \cdot$ Luca Incrocci $^{2} \cdot$ Anna Mensuali-Sodi $^{1}$
}

Received: 9 August 2021 / Revised: 9 November 2021 / Accepted: 9 November 2021 / Published online: 25 February 2022

(c) The Author(s) 2022

\begin{abstract}
Crocus sativus $\mathrm{L}$. is a crop grown for spice production, and large amounts of residues from the flowers are produced during the process. The underutilized by-product from saffron spice production, the $C$. sativus tepals, was investigated as a promising raw material of natural bioactive compounds using light spectrum manipulation in controlled environments. The plants were grown under either light-emitting diodes (LEDs) or natural light (NL, greenhouse). LED experiments were performed in controlled-environment chambers $\left(120 \mu \mathrm{mol} \mathrm{m}{ }^{-2} \mathrm{~s}^{-1}\right.$ of photosynthetically active radiation, $18^{\circ} \mathrm{C}, 16$-h photoperiod). The LED treatments used were as follows: (i) red $K=660 \mathrm{~nm}(62 \%)$ and blue $K=450 \mathrm{~nm}$ (38\%) (RB); and (ii) red $K=660 \mathrm{~nm}$ (50\%), green $\Lambda=500-600 \mathrm{~nm}(12 \%)$, and blue $K=450 \mathrm{~nm}$ (38\%) (RGB). Flower growth parameters, total phenols, total flavonoids, flavonols, flavonol glycosides, and antioxidant properties were measured in harvested tepals. Floral by-products from plants grown under the two LED treatments accumulated higher amounts of antioxidant compounds compared to those of plants grown under NL. The total flavonoids content was significantly enhanced in the RGB LED treatment, while the corolla fresh weight significantly declined in the same treatments. The higher content of bioactive secondary metabolites in plants grown under both RB and RGB light environments resulted in increased antioxidant capacity measured by DPPH free-radical scavenging capacity and the ferric reducing antioxidant power method. These results indicate that manipulation of LED spectra could boost secondary metabolites and antioxidant capacity to obtain phytochemically enriched floral byproducts with superior functional quality.
\end{abstract}

Keywords Saffron $\cdot$ Agricultural residues $\cdot$ LEDs $\cdot$ Phenols $\cdot$ Antioxidant capacity $\cdot$ Secondary metabolism

\section{Introduction}

Agriculture and agro-industrial processing are responsible for producing massive amounts of agri-food wastes and byproducts. Disposal of agricultural wastes causes significant economic and environmental problems by contributing to greenhouse gas emissions (Girotto et al. 2015). However,

Communicated by Sanghyun Lee.

Alice Trivellini

alice.trivellini@gmail.com

1 Institute of Life Sciences, Scuola Superiore Sant'Anna, Piazza Martiri della Libertà 33, 56127 Pisa, Italy

2 Department of Agriculture, Food and Environment, Università Degli Studi Di Pisa, Via del Borghetto 80, 56124 Pisa, Italy

3 Department of Agricultural and Environmental Sciences, Università Degli Studi Di Milano, 20133 Milano, Italy many of these residues are generally considered sources of valuable bioactive compounds (such as micro- and macronutrients, dietary fibers, lipids, starch, proteins, vitamins, and secondary metabolites with antioxidant biological functions) that could find applications in the food, cosmetics, and pharmaceutical industries due to their antioxidant, antimicrobial, and health-promoting properties (Varzakas et al. 2016).

Therefore, the recovery and valorization of plant residues (waste) is a promising strategy to minimize the ecological impact through circular economy models and to create sustainable products.

C. sativus $\mathrm{L}$. flowers are grown worldwide to produce the valuable saffron spice. Commercial saffron is made from the dried stigmas of these flowers, and it is considered to be the most expensive food spice in the world due to the meticulous manual operations needed for its production and the high labor cost (Giupponi et al. 2019). The flowers of $C$. sativus are collected early in the morning to avoid color and quality loss of stigmas, and then stigmas are separated from 
the rest of the flowers (Giupponi et al. 2019). Moreover, this work is conducted only a few days a year and for only a few hours a day, and all of the other activities (field preparation, corms planting, weeding, etc.) are performed manually (Husaini et al. 2010). The principal producers and exporting countries (Iran, Afghanistan, and India) are located in Asia (Jouki et al. 2013a; OEC 2019). In recent years demand for this spice has increased due to Asian population growth (Arslanalp et al. 2019) and to the popularity of Asian cooking worldwide (Giupponi et al. 2019).

The phytochemical composition of saffron spice gives aroma, color, and flavor to food. Crocetin esters are responsible for saffron coloring, generating a range of yellowish-red hues (Moratalla-Lopez et al. 2019). Picrocrocin is the foremost compound responsible for the bitter taste, and safranal is the most important component of the volatile fraction contributing to saffron's distinctive aroma (Carmona et al. 2006). To avoid microbial growth in saffron stigmas, some studies used $\gamma$-irradiation and modified atmosphere packaging to prolong the shelf life without any significant quality deterioration (Jouki et al. 2011, Jouki and Khazaei, 2013b).

Saffron is not only a culinary condiment, but its flowers are also a rich source of health-promoting phytochemicals, including phenols, anthocyanins, flavonoids, and carotenoids. The stigmas have been reported to have high levels of carotenoids, and the petals are a rich source of flavonoids and anthocyanins (Hosseini et al. 2018, Jadouali et al. 2017). The positive effects on human health of these phytochemicals have been widely documented, including the antioxidant, anti-inflammatory, anti-depressant, and anti-carcinogenic benefits (Ahmad et al. 2005; Hosseinzadeh et al. 2007; Talaei et al. 2015; Bathaie et al. 2013; Kyriakoudi et al. 2015). The antioxidant activity is mainly linked to polyphenol compounds, such as kaempferol and quercetin (flavonoids) (Colombo et al. 2019; Riahi-Chebbi et al. 2019). Serrano-Díaz et al. (2014) demonstrated the absence of cytotoxicity in an aqueous extract, showing that this extract can be safely added to foods. Moreover, tepal extract has been reported to be a natural source of antioxidants and used as an ingredient to develop high-quality cosmetic products, since it plays a role in delaying the skin aging process (Acero de Mesa et al. 2018).

The traditional method of saffron production employs manual flower harvesting and stigma separation. After separating stigmas from flowers, the other flower components, including tepals, stamens, and styles, are dismantled. To produce $1 \mathrm{~kg}$ of saffron, dried pistils of approximately 200,000 flowers are needed with $63 \mathrm{~kg}$ of floral bio-residues (Serrano-Diaz 2013). The tepals account for a majority of the total weight of the whole saffron flower at $78.4 \%$, followed by stamens at $13.4 \%$, stigmas at $7.4 \%$, and styles at $0.7 \%$ (Moratalla-Lopez et al. 2019). Previous studies reported that large quantities of saffron floral residues are not used and thrown away after harvesting, and these byproducts account for about 86 to $93 \%$ of the mass of saffron flowers (Moratalla-Lopez et al. 2019). In this context, the range of beneficial properties of $C$. sativus tepals make this by-product a sustainable source of promising phytochemicals (mainly polyphenols) to be used in food, nutraceutical, and cosmetic industries (Trivellini et al. 2016).

The content of polyphenols, in particular flavonoids, may be related to the response of plants to environmental conditions, such as light conditions (Tattini et al. 2005; Agati et al. 2011). The spectrum and direction of light-emitting diodes (LEDs) can be modulated to control light intensity and decouple lighting from heating (Singh et al. 2015). This allows not only control of the growth, development, and yield of plants, but also improvement of overall quality and energy use. The phytochemical content can be effectively modulated by controlling the spectral composition of LEDs to promote the most suitable composition of plant tissue for nutraceuticals. Several studies, recently reported and reviewed by Paradiso and Proietti (2021), investigated the influence of light-quality treatments, using red (R), blue (B), green (G) LEDs and their ratios, on secondary metabolism to regulate the amount of functional metabolites of several horticultural crops. In general, in response to select spectral bandwidths (R, B, G, RB, and RGB), functional quality was improved by promoting the accumulation of antioxidant compounds (i.e., phenolic acids, flavonoids, carotenoids, and antioxidant capacity).

In this study, the underutilized by-product from saffron spice production, the $C$. sativus tepals, was investigated as a promising raw material of natural bioactive compounds with possible applications in the food and cosmeceutical industries. C. sativus plants were grown in a growth chamber to control flower organ development and secondary metabolite accumulation using light spectrum manipulation to obtain a standard production of high-value bioactive compounds from floral residues (Fig. 1).

\section{Materials and methods}

\subsection{Plant materials}

Saffron (Crocus sativus L.) bulbs were purchased from Floriana Bulbose (Monte Porzio Catone, Roma, Italy). The bulbs had a diameter of $3 \mathrm{~cm}$ and before transplanting were stored in a refrigerator at $4{ }^{\circ} \mathrm{C}$ with $80 \%$ humidity for 50 days to promote a good vegetative-flowering restart.

\subsection{Plant growth conditions}

Saffron bulbs were transplanted in plastic perforated boxes $(50 \mathrm{~cm} \times 30 \mathrm{~cm} \times 25 \mathrm{~cm})$ covered by non-woven 


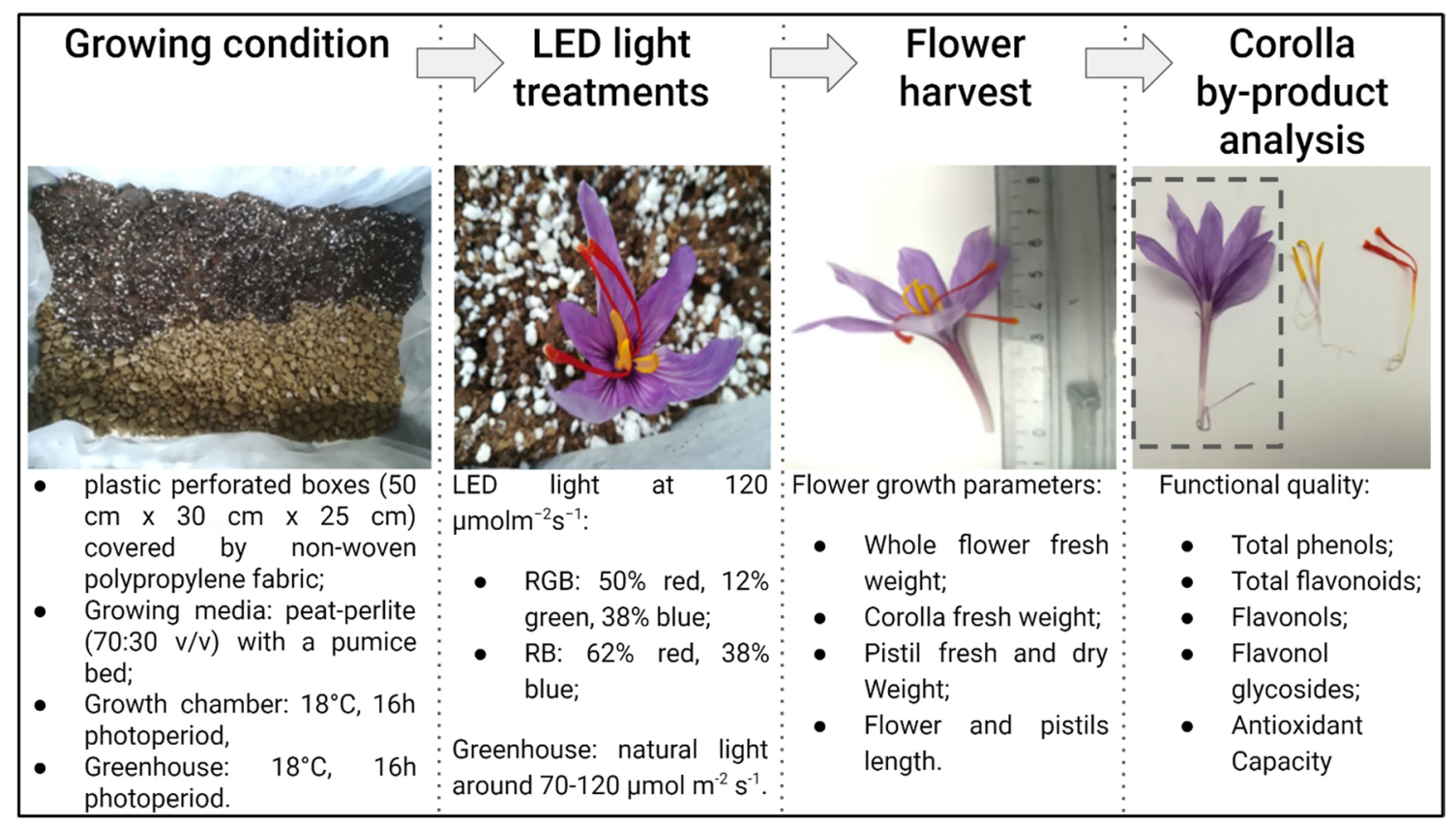

Fig. 1 Schematic representation of overall experimental design for Crocus sativum plant growth, LED treatments, and corolla by-product biochemical analysis

polypropylene fabric to control irrigation runoff. The growth medium used was peat-perlite $(70: 30 \mathrm{v} / \mathrm{v})$ with a bed of pumice ( $5 \mathrm{~cm}$ high) to improve water drainage as saffron prefers soils with a high stone-skeleton. For each box, 20 bulbs were planted in five rows with four bulbs in each row. The transplanting took place on October 31, 2019 at the Department of Agriculture, Food and Environment of the University of Pisa, Italy $\left(43^{\circ} 70^{\prime} \mathrm{N} 10^{\circ} 43^{\prime} \mathrm{E}\right)$. The plants were cultivated in a growth chamber at constant temperature of $18^{\circ} \mathrm{C}$ and photoperiod of 16:8 h. Two different LED lamps were tested: (i) red $\Lambda=660 \mathrm{~nm}(62 \%)$ and blue $\Lambda=450 \mathrm{~nm}(38 \%)$ (RB); and (ii) red $\Lambda=660 \mathrm{~nm}(50 \%)$, -green $\Lambda=500-600 \mathrm{~nm}$ (12\%), and blue $\kappa=450 \mathrm{~nm}(38 \%)$ (RGB). The lighting area was $0.5 \mathrm{~m}^{2}(1.0 \mathrm{~m} \times 0.5 \mathrm{~m})$. The plant photosynthetic quantum flux density, measured $10 \mathrm{~cm}$ above the plants, was $120 \mu \mathrm{mol} \mathrm{m} \mathrm{m}^{-2} \mathrm{~s}^{-1}$. The control plants were placed in plastic perforated boxes $(50 \mathrm{~cm} \times 30 \mathrm{~cm} \times 25 \mathrm{~cm})$ covered by non-woven polypropylene fabric and grown in a glass greenhouse under natural light (NL). The growing conditions were as follows: $18{ }^{\circ} \mathrm{C}$ average temperature, $70-80 \%$ humidity, approximately 15:9 (light/dark)-h photoperiod, and $70-120 \mu \mathrm{mol} \mathrm{m} \mathrm{m}^{-2} \mathrm{~s}^{-1}$ light intensity. In both growing conditions, surface irrigation was employed by applying $3000 \mathrm{~g}$ of water per box.

\subsection{Saffron flower growth parameters}

C. sativus flowers were collected the day after anthesis (to evaluate the metabolic response to the corolla's LED radiation), and the corolla was frozen in liquid nitrogen and stored at $-80^{\circ} \mathrm{C}$ until biochemical analysis. The influence of the different combinations of light treatments were monitored on $C$. sativus harvested flowers by measuring the length (cm) and weight (g) of the (i) whole flower, (ii) pistil, and (iii) corolla.

\subsection{Bioactive molecule extraction from tepals}

Acidified $80 \%$ methanol (containing $1 \%$ hydrochloric acid) was used for the extraction of flavonolglycosides and total anthocyanins; pure methanol solution was used for the extraction of all the other bioactive components. The extraction protocol reported by Maggini et al. $(2013,2018)$ was used with modifications. The saffron corolla samples $(0.2 \mathrm{~g})$ were soaked with $2.5 \mathrm{~mL}$ extraction solvent in $10-\mathrm{mL}$ test tubes. The samples were sonicated in an ice bath for $30 \mathrm{~min}$. The sonication was repeated four times, and the tubes were stored overnight at $-20{ }^{\circ} \mathrm{C}$. Then, the supernatant liquid was separated by centrifugation for $4 \mathrm{~min}$ at $2500 \mathrm{rpm}$. The pellet of each sample was extracted again with $2.5 \mathrm{~mL}$ of extraction solvent. The supernatants were pooled together before subsequent analysis. The results were calculated on a fresh weight (FW) basis.

\subsection{Total flavonoids}

Total flavonoids were determined spectrophotometrically as described by Kim et al. (2003): $240 \mu \mathrm{L}$ of $\mathrm{NaNO}_{2}$ (5\%) was 
added to $400 \mu \mathrm{L}$ of methanolic extract, and after 5 min and stirring, $160 \mu \mathrm{L}$ of $\mathrm{AlCl}_{3}$ (10\%) was added. The samples were shaken again and let stand for $5 \mathrm{~min}$. Finally, $1.6 \mathrm{~mL}$ of $\mathrm{NaOH}(1 \mathrm{M})$ and $800 \mu \mathrm{L}$ of water were added. The spectrophotometer reading was at $\Lambda 510 \mathrm{~nm}$. The results obtained were expressed as milligrams of quercetin equivalents per gram of sample.

\subsection{Flavonol glycosides and total anthocyanins}

Flavonol glycosides and total anthocyanins were measured as reported by Hrazdina et al. (1982). The amount of total flavonol glycosides was measured spectrophotometrically on the acidic methanol extracts. Absorbance was read at $360 \mathrm{~nm}$. Total flavonol glycoside concentration was expressed as quercetin equivalent in milligrams per gram of sample. For the quantification of total anthocyanins, the absorbance of the same extract was read at $530 \mathrm{~nm}$, and the results were expressed as milligrams of cyanidin-3-glucoside equivalent per gram of fresh weight $\left(\mathrm{g}^{-1} \mathrm{FW}\right)$, using the value $38,000 \mathrm{M}^{-1} \mathrm{~cm}^{-1}$ for the molar absorptivity.

\subsection{Flavonols}

Flavonols were determined according to Radovanovicet al. (2010). The sample extracted in methanol was diluted 1:10 with ethanol (10\% in water). Subsequently, $500 \mu \mathrm{L}$ of this dilution was added to $500 \mu \mathrm{L}$ of $\mathrm{HCl}(0.1 \%$ in ethanol) and to $2 \mathrm{~mL}$ of $\mathrm{HCl}$ ( $2 \%$ in water). The spectrophotometric reading was at $\kappa 360 \mathrm{~nm}$, and the results obtained were expressed as milligram equivalents of quercetin per gram of sample.

\subsection{Total phenols}

The amount of total phenols was determined by the FolinCiocalteu phenol reagent, according to the method reported by Kang and Saltveit (2002) with minor modifications (Maggini et al. 2018). An aliquot of $100 \mu \mathrm{l}$ methanol extract was mixed with $2.0 \mathrm{~mL}$ of distilled water and $300 \mu \mathrm{L}$ of FolinCiocalteu phenol reagent. The mixture was incubated for 4 min at room temperature $\left(20-24^{\circ} \mathrm{C}\right)$ and then $7.5 \%$ sodium carbonate $(1.6 \mathrm{~mL})$ was added. Then, the mixture was stored in the dark at room temperature for $2 \mathrm{~h}$. Absorbance was then measured at $765 \mathrm{~nm}$. For calibration, standard solutions of gallic acid $\left(0-500 \mathrm{mg} \mathrm{L}^{-1}\right)$ were prepared. The concentration of total phenols was expressed in terms of gallic acid equivalent as milligrams of gallic acid per gram of fresh weight $\left(\mathrm{g}^{-1} \mathrm{FW}\right)$.

\subsection{Antioxidant capacity}

The ferric reducing antioxidant power (FRAP) assay was performed following the method described by Benzie and
Strain (1996). For this assay, $2.0 \mathrm{~mL}$ of acetate buffer (0.25 M, pH 3.6), $900 \mu \mathrm{L}$ of freshly prepared FRAP reagent ( $2 \mathrm{mM}$ ferric chloride and $1 \mathrm{mM}$ 2,4,6-tris(2-pyridyl)-s-triazine in acetate buffer), and $100 \mu \mathrm{L}$ plant methanolic extract were used. Calibration was performed using a standard curve prepared with ammonium ferrous sulfate standard solutions, containing $0-1000 \mu \mathrm{M}$ ferrous ion. The absorbance at $593 \mathrm{~nm}$ was determined, and the results were expressed as micromole $(\mu \mathrm{mol})$ of $\mathrm{Fe}^{2+}$ equivalents per gram of fresh weight $\left(\mu \mathrm{mol} \mathrm{Fe}{ }^{2+}\left(\mathrm{g}^{-1} \mathrm{FW}\right)\right.$.

The DPPH (2,2-diphenyl-1-picrylhydrazyl) radical scavenging activity assay was conducted according to Dudonné et al. (2009) with slight modifications as reported by Maggini et al. (2018). A 100- $\mu \mathrm{L}$ aliquot of methanol extract was mixed with $2.97 \mathrm{~mL}$ of methanol DPPH solution $(20 \mathrm{mg}$ $\mathrm{L}^{-1}$ ). A blank solution was also prepared by replacing the plant extract with methanol. The mixture was incubated at room temperature in the dark for $45 \mathrm{~min}$; then, absorbance was measured at $515 \mathrm{~nm}$. The percentage inhibition of the DPPH radical per gram tissue was calculated from the absorbance values of the blank (Ablank) and from the sample (Asample) as follows:

$\%$ Inhibition $\mathrm{g}^{-1} \mathrm{FW}=100 \cdot[($ Ablank - Asample $) /$ Ablank $] / \mathrm{g} \mathrm{FW}$

where Ablank is the absorbance of the blank solution (absorbance of DPPH solution), and Asample is the absorbance of the testing sample solution.

\subsubsection{Statistical analysis}

Statistical analysis was performed using PRISM 9 software (GraphPad Software, San Diego, CA, USA). One-way ANOVA was used to analyze the effects of two multispectral LEDs, as the only light sources, and a natural greenhouse light condition, on flower organ development and secondary metabolite accumulation. Significant differences among means values were determined by Tukey's post-test at $p<0.05$. Values are means of at least 10 independent biological samples. The whole experiment was independently repeated twice.

\section{Results}

\subsection{Effects of light spectrum manipulation on flower growth}

The plants grown under the RB-LED treatment showed the highest whole flower and corolla fresh weights (FWs), greater than those of the control (natural light, NL) and RGB-LED groups (Table 1). Plants grown under RB-LED and RGB-LED conditions showed a significant increase in 
Table 1 Effect of different light environments on flower growth parameters

\begin{tabular}{llllllc}
\hline Treatment & Pistils $(\mathrm{g} \mathrm{FW})$ & Pistils $(\mathrm{g}$ DW) & Flower Lenght $(\mathrm{cm})$ & Pistil Lenght $(\mathrm{cm})$ & Whole Flower (g FW) & Tepals (g FW) \\
\hline NL & $0.035 \pm 0.007^{\mathrm{y}}$ & $0.004 \pm 0.0008^{\mathrm{y}}$ & $6.41 \pm 0.44^{\mathrm{y}}$ & $4.06 \pm 0.28^{\mathrm{y}}$ & $0.35 \pm 0.08^{\mathrm{y}}$ & $0.28 \pm 0.06^{\mathrm{y}}$ \\
RGB & $0.040 \pm 0.006^{\mathrm{z}}$ & $0.005 \pm 0.0009^{\mathrm{z}}$ & $6.98 \pm 0.51^{\mathrm{z}}$ & $4.36 \pm 0.28^{\mathrm{z}}$ & $0.39 \pm 0.08^{\mathrm{zy}}$ & $0.30 \pm 0.06^{\mathrm{y}}$ \\
RB & $0.041 \pm 0.007^{\mathrm{z}}$ & $0.005 \pm 0.0010^{\mathrm{z}}$ & $7.22 \pm 0.37^{\mathrm{z}}$ & $4.42 \pm 0.32^{\mathrm{z}}$ & $0.43 \pm 0.06^{\mathrm{z}}$ & $0.34 \pm 0.05^{\mathrm{z}}$ \\
\hline
\end{tabular}

Analysis of variance was used for comparisons (one-way ANOVA). Means within each column followed by different letters are significantly different ( $p<0.05$; Tukey's multiple range test, $n>5$ ). NL, natural light; RB, red-blue LED combination; RGB, red-green-blue light combination; FW, fresh weight; DW, dry weight

both pistil FW and dry weight (DW) compared to the NL group (Table 1). There were no significant differences in these parameters (pistil FW and DW) between the RB-LED and RGB-LED groups. Both flower and pistil lengths of plants grown under RB-LED and RGB-LED conditions were greater than that of the NL plant, which showed the lowest level of all groups (Table 1). There were no significant differences in flower and pistil lengths between the RB-LED and RGB-LED groups.

\subsection{Effects of light spectrum manipulation on total flavonoid, flavonol glycoside, and flavonol accumulation}

The combination of red, green, and blue light in RGB significantly increased the content of total flavonoids in $C$. sativus corolla, about $14.92 \mathrm{mg} / \mathrm{g}$ compared to 11.72 and $9.24 \mathrm{mg} / \mathrm{g}$ in the RB-LED and NL groups, respectively (Fig. 2a). The corolla of plants grown under RB-LED and RGB-LED conditions had significantly increased flavonol glycosides ( 7.64 and $8.23 \mathrm{mg} / \mathrm{g}$ ) compared to the control $(5.01 \mathrm{mg} / \mathrm{g})$ (Fig. 2b). Similarly, the content of flavonols in both LED treatments $(2.89 \mathrm{mg} / \mathrm{g}$ under RB and $2.54 \mathrm{mg} / \mathrm{g}$ under RGB) was significantly enhanced compared to the NL group $(0.93 \mathrm{mg} / \mathrm{g})$ (Fig. 2c). No significant differences in flavonol glycosides and flavonol concentrations were observed between LED treatments. Overall, these results showed that the LEDs positively and significantly influenced the total flavonoid, flavonol glycoside, and flavonol contents in tepals compared to the NL treatment.

\subsection{Effects of light spectrum manipulation on total phenols}

The concentration of total phenols in the corolla of plants grown under RB-LED $(8.81 \mathrm{mg} / \mathrm{g})$ and RGB-LED $(9.46 \mathrm{mg} / \mathrm{g})$ conditions was significantly higher than that of the NL plants, which showed the lowest level $(6.77 \mathrm{mg} / \mathrm{g})$ of all groups (Fig. 3). There were no significant differences in total phenols content between the RB-LED and RGB-LED groups.
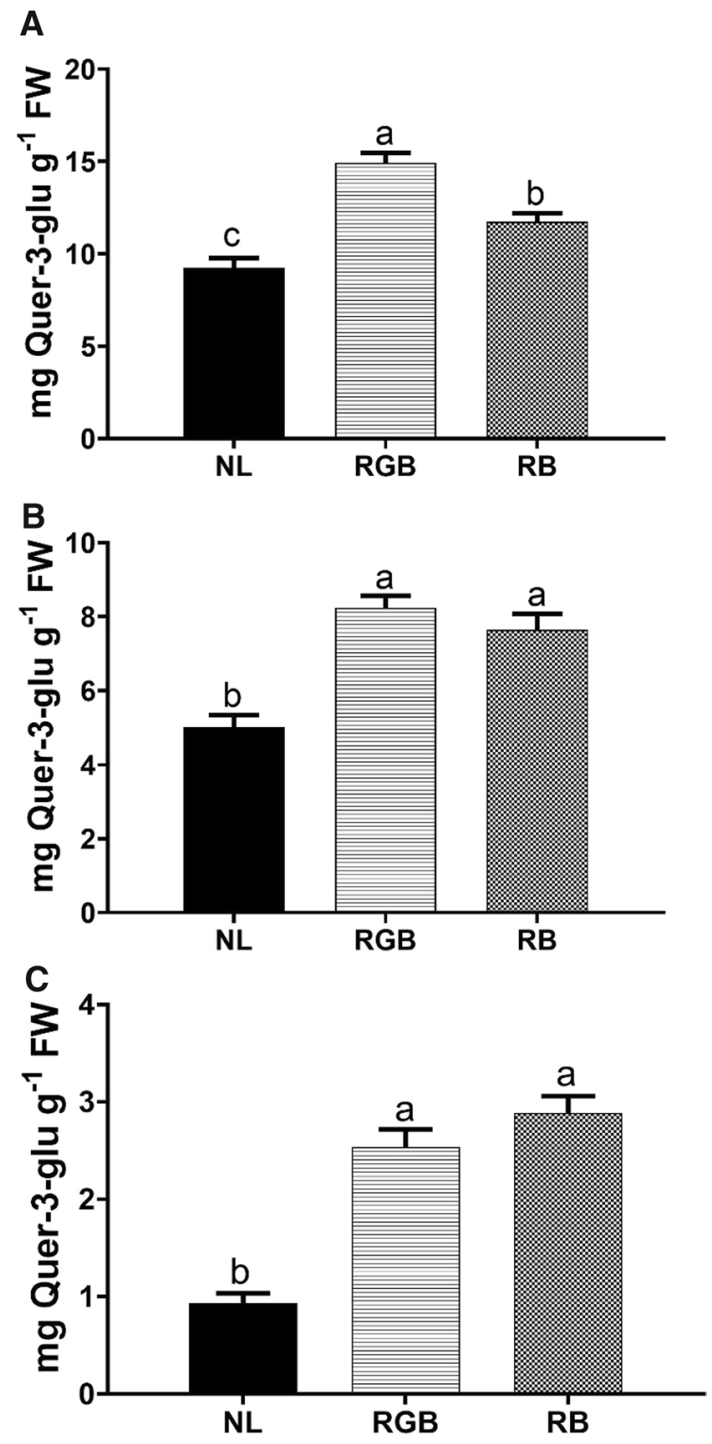

Fig. 2 The concentration of total flavonoids (a), flavonol glycosides (b), and flavonols (c) in the tepals of Crocus sativus affected by different light environments. Data are shown as means with at least 10 independent biological replicates, and error bars indicate standard error (SE). Data were subjected to one-way analysis of variance, and differences were analyzed by Tukey's post-test. Different letters denote significant differences at $p<0.05$. NL, natural light; RB, redblue LED combination; RGB, red-green-blue light combination 


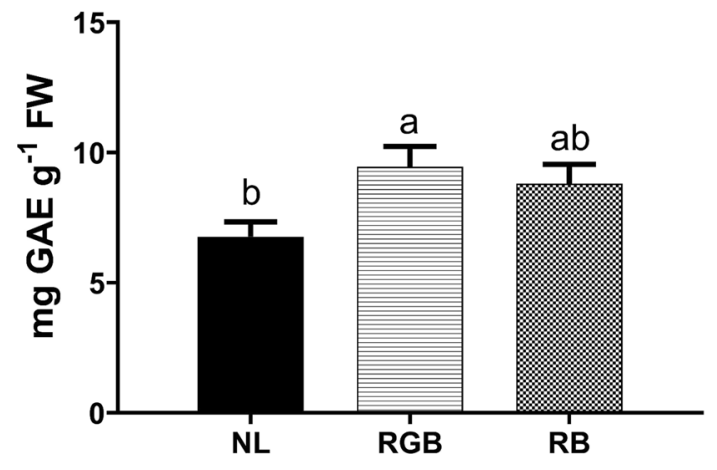

Fig. 3 Total phenol content in the tepals of Crocus sativus affected by different light environments. Data are shown as means with at least 10 independent biological replicates, and error bars indicate standard error (SE). Data were subjected to one-way analysis of variance, and differences were analyzed by Tukey's post-test. Different letters denote significant differences at $p<0.05$. NL, natural light; RB, redblue LED combination; RGB, red-green-blue light combination

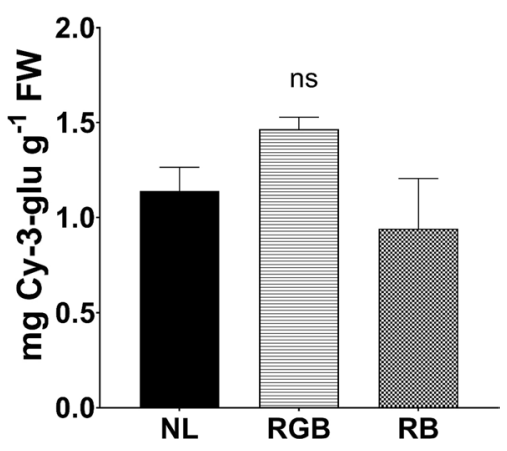

Fig. 4 Total anthocyanin content in the tepals of Crocus sativus affected by different light environments. Data are shown as means with at least 10 independent biological replicates, and error bars indicate standard error (SE). Data were subjected to one-way analysis of variance, and differences were analyzed by Tukey's post-test. Different letters denote significant differences at $p<0.05$. ns, not significant. NL, natural light; RB, red-blue LED combination; RGB, redgreen-blue light combination

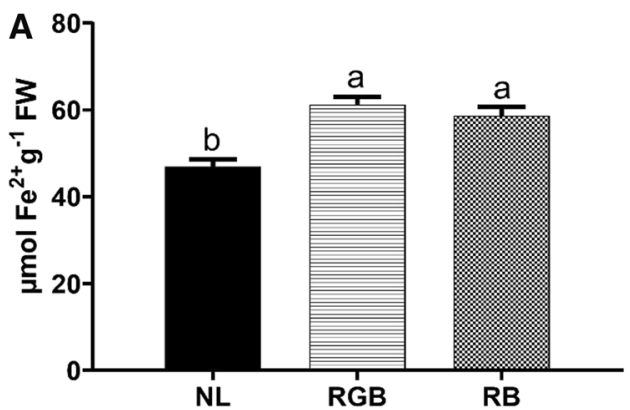

Fig. 5 Antioxidant capacity of Crocus sativus tepals affected by different light environments. (a) Reducing capacity of extracts from tepals of Crocus sativus affected by different light environments as determined by a FRAP test. (b) Radical-scavenging activity of extracts from tepals of Crocus sativus affected by different light environments determined by a DPPH test. Data are shown as means with

\subsection{Effects of light spectrum manipulation on total anthocyanins}

The concentration of total anthocyanins tended to be higher (but not statistically significant) in the tepals of plants grown under the RGB light environment than in the other light treatments (Fig. 4).

\subsection{Light spectrum manipulation affects antioxidant capacity}

The antioxidant power of $C$. sativus corolla from plants grown under RB-LED and RGB-LED conditions was determined using both FRAP and DPPH assays (Fig. 5), and the results obtained with the two independent methods were significantly correlated ( $p$ value $<0.05$ ). In both LED treatments, the ferric-reducing capacity of the antioxidants (Fig. 5a) and the ability of antioxidants to scavenge the DPPH radical (Fig. 5b) were significantly higher compared to those observed in NL group.

\section{Discussion}

Light quality, which refers to the spectral composition of light, is a key regulator of plant growth through various photoreceptors, which are involved in light sensing and downstream signal transduction (Ward et al. 2005; Weller and Kendrick 2008). Different wavelengths of light are perceived by a complex network of photosensory pathways that enable plants to selectively activate individual pathways by inducing the expression of genes related to several physiological and metabolic functions (Whitelam and Halliday 2007; Li et al. 2012a, b).

In this study, C. sativus, a high-value culinary and medicinal plant, was selected to investigate the potential

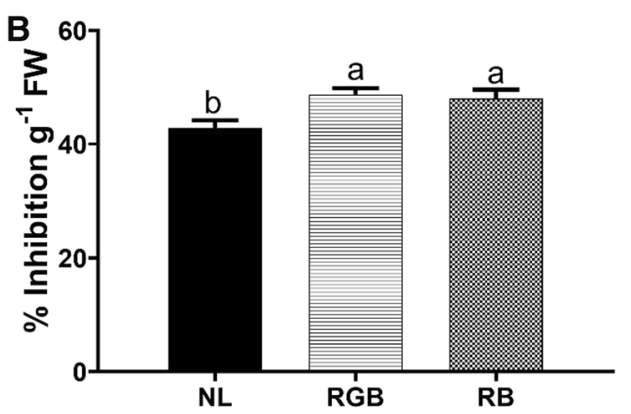

at least 10 independent biological replicates, and error bars indicate standard error (SE). Data were subjected to one-way analysis of variance, and differences were analyzed by Tukey's post-test. Different letters denote significant differences at $p<0.05$. NL, natural light; $\mathrm{RB}$, red-blue LED combination; RGB, red-green-blue light combination 
of two different LED treatments for targeted plant physiological responses on its by-product, the corolla, proposing this residue as a novel source of enriched functional ingredients or raw material for the food and cosmeceutical industries. The combined LED treatments were accurately designed to uniformly provide the following light environment: (i) $50 \%$ red $(660 \mathrm{~nm}) / 12 \%$ green $(500-600 \mathrm{~nm}) / 38 \%$ blue $\left(450 \mathrm{~nm}\right.$ ) at $120 \mu \mathrm{molm}^{-2} \mathrm{~s}^{-1}$ (RGB); and (ii) $62 \%$ red $(660 \mathrm{~nm}) / 38 \%$ blue $(450 \mathrm{~nm})$ at $120 \mu \mathrm{molm}^{-2} \mathrm{~s}^{-1}(\mathrm{RB})$. Plants grown under natural light (NL) were used as the control. Blue and red wavelengths are important for photosynthesis and have the greatest impact on plant growth due to the absorption peaks of chlorophyll molecules by increasing stomatal opening, electron transport, Rubisco activity, polyphenol concentration, and pigment production (Ouzounis et al. 2016; Olle and Virsile 2013; Taulavuori et al. 2013). Whole-plant studies suggest that supplemental G light (ranging from 24 to $10 \%$ ) may improve plant growth in combination with $\mathrm{R}$ and $\mathrm{B}$ by increasing total photosynthesis in the individual leaves, as well as by transmitting to lower leaf layers (Broadersen and Vogelmann 2010; Johkan et al. 2012). In this study, the whole flower and corolla of $C$. sativus had the highest fresh weight when grown under RB than under RGB or NL light environment conditions. $\mathrm{R}$ and $\mathrm{B}$ wavelengths correspond to the absorption spectra of chlorophyll a and $\mathrm{b}$, and in general, a combination of these wavelengths with a high $\mathrm{R}: \mathrm{B}$ ratio have been shown to promote plant growth by achieving greater biomass production compared with $\mathrm{R}$ or B wavelengths alone (Amoozgar et al. 2017; Wollaeger and Runkle 2014; Fan et al. 2013; Li and Kubota 2009). Compared with $R$ and $B$ wavelengths, $G$ light has not been considered to be effective for plant treatments due to its low capacity for chlorophyll absorption (Kopsell et al. 2014; Paradiso and Proietti 2021). However, $\mathrm{G}$ wavelengths have high transmittance and reflectance, and penetrate deeper in the plant canopy, which could potentially increase plant photosynthesis (plant yield) and regulate secondary metabolism, when appropriately combined with R and B wavelengths (Dou et al. 2019a; Dou et al. 2017; Wang and Folta 2013). The inclusion or not of $\mathrm{G}$ wavelengths in combination with $\mathrm{RB}$ resulted in greater pistil and flower length and FW compared to plants grown under NL conditions. However, G light reversed the effects of RB wavelengths on corolla biomass accumulation. Similar to that observed in basil and brassica (Dou et al. 2020), in C. sativus the inclusion of $\mathrm{G}$ wavelengths decreased corolla biomass (on FW basis) compared with that of plants grown under $\mathrm{R}$ and $\mathrm{B}$ wavelength combinations with a similar B percentage (38\%). The addition of $\mathrm{G}$ light to a RB background has previously been shown to reverse B light-induced stomatal opening, resulting in lower plant photosynthesis and plant biomass, which can be used to make small adjustments in plant growth and secondary metabolism to best exploit prevailing conditions (Dou et al. 2020; Folta and Maruhnich 2007; Talbott et al. 2006).

Previous research has demonstrated that light quality is not only involved in plant photomorphogenesis but also stimulates plant secondary metabolism via the photosensory network driven by photoreceptor pathways (Jones 2018; Dou et al. 2017; Zhang and Folta 2012). Specific wavelengths, such as R, B, and G, enhanced the concentration of certain phytochemicals in several horticultural plants compared with white light or sunlight, and the level of enhancement is dependent on species, compounds, and light treatments (Dou et al. 2020; Taulavuori et al. 2018, 2016; Lobiuc et al. 2017; Arena et al. 2016). Polyphenols are secondary metabolites found in plants with various structures including phenolic acids, flavonoids, anthocyanins, flavonols, and numerous derivates (Cheynier 2015). These compounds are generally synthesized to cope with environmental challenges (i.e., UV radiation) and biotic stress (Mosadegh et al. 2021; Sharma et al. 2019). Moreover, these metabolites have extremely diverse biological properties, which make them unique and promising natural ingredients to be used in the food, pesticide, pharmaceutical, and cosmeceutical industries (Trivellini et al. 2016). Polyphenols have been reported to be affected by specific spectral bandwidths in the light environment in species-dependent and phytochemical-dependent manners, providing evidence that the effect of light can target the modulation of plant secondary metabolism to produce phytochemically enriched plants of high functional quality (Gam et al. 2020; Kyriacou et al. 2019; Mosadegh et al. 2018; Taulavuori et al. 2013; Stutte et al. 2009; Li and Kubota 2009). For example, phytochemicals such as phenolics, flavonoids, and anthocyanins were highest in a B light environment in Eruca sativa, Rehmannia glutinosa, and Perilla frutescens plants (Taulavuori et al. 2018; Lee et al. 2014; Manivannan et al. 2015), while rosmarinic acid (a phenolic acid) concentration in leaf tissues of Ocinum basilicum was enhanced under R light (Shiga et al. 2009). Most of the health benefits of saffron have been recognized since ancient times, and the corolla of $C$. sativus possesses high phenolic content and excellent antioxidant properties (Serrano-Diaz et al. 2012; Menghini et al. 2018; Caser et al. 2020). In agreement with Caser et al. (2020), this study shows that $C$. sativus tepals are rich in total phenols. LED treatments of $50 \% \mathrm{R}(660 \mathrm{~nm}) / 12 \% \mathrm{G}(500-600 \mathrm{~nm}) / 38 \% \mathrm{~B}$ $(450 \mathrm{~nm})(\mathrm{RGB})$ and $62 \% \mathrm{R}(660 \mathrm{~nm}) / 38 \% \mathrm{~B}(450 \mathrm{~nm})$ at $120 \mu \mathrm{mol} \mathrm{m} \mathrm{m}^{-2} \mathrm{~s}^{-1}$ (RB) cause significantly higher total flavonoid, flavonol, and flavonol glycoside content than saffron plants grown under natural light. Interestingly, the concentration of total flavonoids in corolla increased significantly only by the addition of $\mathrm{G}$ light to a RB light environmental background. Also, the total anthocyanin content tended to 
be higher under the RGB-LED treatment, although it was not significantly different among the different light environments. In parallel with a higher concentration of total phenol bioactive compounds, poor biomass accumulation occurred in the corolla, which is in agreement with growth-defense trade-offs in which defense activation against adverse conditions through the activation of secondary metabolism generally comes at the expense of plant growth (Taulavuori et al. 2013; Huot et al. 2014). R and B light or combined spectra of these wavelengths are widely known to enhance the concentration of phenols, up-regulating the expression of genes or key enzymes involved in their biosynthetic pathway (Cuong et al., 2019; Li et al. 2010; Meng et al. 2004). However, only a few studies were conducted on the interactions between $\mathrm{G}$ and RB light combinations. In general, the inclusion of $\mathrm{G}$ wavelengths tends to reverse the $\mathrm{B}$ wavelength-induced phytochemical accumulation in a range of plant species such as Arabidopsis, basil, and lettuce (Zhang and Folta 2012; Dou et al. 2019; Pennisi et al. 2019). In $C$. sativus corolla, the inclusion of $\mathrm{G}$ light had a positive effect on secondary metabolites. Moreover, like the concentrations of key secondary metabolites (total phenols, total flavonoids, flavonols, and flavonol glycosides), the antioxidant capacity of $C$. sativus tepals also was favored by both RGB and RB light environments compared to natural light. In agreement with our findings, Dou et al. (2020) reported an increase in concentration and total amounts of bioactive molecules, the anthocyanins, in green kale with the addition of $\mathrm{G}$ wavelengths to a RB background, suggesting a species-specific effect on phytochemical accumulation by $\mathrm{G}$ light, which is dependent on the RB ratio.

\section{Conclusion}

Overall, the results reported here demonstrate the ability to influence the growth, development, and functional quality of C. sativus agricultural by-products through the manipulation of the light spectrum.

(i)Both LED treatments (RB and RGB) increased total flavonoids, flavonols, flavonol glycosides, and antioxidant capacity;

(ii)Plants grown under RB light obtained the highest tepals biomass while reducing total phenol concentration compared to the NL (control) light environment;

(iii)The inclusion of $\mathrm{G}$ wavelengths had positive effects on phenolics accumulation (i.e.; total flavonoids) and no effect on biomass accumulation compared to the NL (control) light environment.

Therefore, the use of LED treatments, specifically RGB, might lead to greater accumulation of bioactive components and represent a promising strategy for the valorization of floral residues as a functional-enriched ingredient for the food and cosmeceutical industries.

Acknowledgements This work was supported by Scuola Superiore Sant'Anna (Italy) and Department of Agriculture, Food and Environment (Università degli Studi di Pisa, Italy). MO was supported by a $\mathrm{PhD}$ fellowship in Agrobioscience by Scuola Superiore Sant'Anna.

Author contributions MO conducted the experiments and contributed to writing of the manuscript. AT and AM designed the study, analysed the data, and contributed to writing of the manuscript. MO and MP contributed to preparation of figures and tables. AF and IL reviewed and edited the manuscript. AM supervised the research project.

\section{Declarations}

Conflict of interest The authors declare that they have no known competing financial interests or personal relationships that could have appeared to influence the work reported in this paper.

Open Access This article is licensed under a Creative Commons Attribution 4.0 International License, which permits use, sharing, adaptation, distribution and reproduction in any medium or format, as long as you give appropriate credit to the original author(s) and the source, provide a link to the Creative Commons licence, and indicate if changes were made. The images or other third party material in this article are included in the article's Creative Commons licence, unless indicated otherwise in a credit line to the material. If material is not included in the article's Creative Commons licence and your intended use is not permitted by statutory regulation or exceeds the permitted use, you will need to obtain permission directly from the copyright holder. To view a copy of this licence, visit http://creativecommons.org/licenses/by/4.0/.

\section{References}

Acero de Mesa N, Muñoz-Mingarro D, Bielsa Pons EM.: Biowaste saffron extracts as active ingredients of cosmetic products antioxidants. ES2646415B128 September 2018.

Agati G, Cerovic ZG, Pinelli P, Tattini M (2011) Light-induced accumulation of ortho-dihydroxylated flavonoids as nondestructively monitored by chlorophyll fluorescence excitation techniques. Environ Exp Bot 73:3-9. https://doi.org/10.1016/j.envexpbot. 2010.10.002

Ahmad AS, Ansari MA, Ahmad M, Saleem S, Yousuf S, Hoda MN, Islam F (2005) Neuroprotection by crocetin in a hemi-parkinsonian rat model. Pharmacol Biochem Behav 81:805-813. https:// doi.org/10.1016/j.pbb.2005.06.007

Amoozgar A, Mohammadi A, Sabzalian MR (2017) Impact of lightemitting diode irradiation on photosynthesis, phytochemical composition and mineral element content of lettuce cv. Grizzly Photosynthetica 55:85-95. https://doi.org/10.1007/s11099-016-0216-8

Arena C, Tsonev T, Doneva D, De Micco V, Michelozzi M, Brunetti C, Centritto M, Fineschi S, Velikova V, Loreto F (2016) The effect of light quality on growth, photosynthesis, leaf anatomy and volatile isoprenoids of a monoterpene-emitting herbaceous species (Solanum lycopersicum L.) and an isoprene-emitting tree (Platanus orientalis L.). Environ Exp Bot 130:122-132. https://doi.org/10. 1016/j.envexpbot.2016.05.014

Arslanalp S, Lee J, Rawat U (2019) Demographics and interest rates in Asia. Jpn World Econ 50:14-24. https://doi.org/10.1016/j.japwor. 2019.03.001 
Bathaie SZ, Hoshyar R, Miri H, Sadeghizadeh M (2013) Anticancer effects of crocetin in both human adenocarcinoma gastric cancer cells and rat model of gastric cancer. Biochem Cell Biol 91:397403. https://doi.org/10.1139/bcb-2013-0014

Benzie IFF, Strain JJ (1996) The ferric reducing ability of plasma (FRAP) as a measure of "Antioxidant power": the FRAP assay. Anal Biochem 239:70-76. https://doi.org/10.1006/abio.1996.0292

Broadersen CR, Vogelmann TC (2010) Do changes in light direction affect absorption profiles in leaves? Funct Plant Biol 37:403-412. https://doi.org/10.1071/FP09262

Carmona M, Zalacain A, Alonso GL.: The Chemical Composition of Saffron: Color, Taste and Aroma. Bomarzo SL Albacete Spain (2006)

Caser M, Demasi S, Stelluti S, Donno D, Scariot V (2020) Crocus sativus L. cultivation in Alpine environments stigmas and tepals as source of bioactive compounds. Agronomy 10:1473. https:// doi.org/10.3390/agronomy10101473

Cheynier V, Tomas-Barberan FA, Yoshida K (2015) Polyphenols: from plants to a variety of food and nonfood uses. J Agric Food Chem 63:7589-7594. https://doi.org/10.1021/acs.jafc.5b01173

Colombo M, Melchiades G, Roberta Michels L, Figueiró F, Bassani V, Ferreira Teixeira H, Koester L (2019) Solid dispersion of kaempferol: Formulation development, characterization, and oral bioavailability assessment. AAPS Pharm Sci Tech 20:106. https:// doi.org/10.1208/s12249-019-1318-y

Cuong D, Ha TW, Park CH, Kim NS, Yeo HJ, Chun SW, Kim C, Park SU (2019) Effects of LED lights on expression of genes involved in phenylpropanoid biosynthesis and accumulation of phenylpropanoids in wheat sprout. Agronomy-Basel 9:307. https://doi.org/ 10.3390/agronomy9060307

Dou H, Niu G, Gu M, Masabni JG (2017) Effects of light quality on growth and phytonutrient accumulation of herbs under controlled environments. Horticulturae 3:2-36. https://doi.org/10.3390/horti culturae 3020036

Dou H, Niu G, Gu M (2019) Photosynthesis, morphology, yield, and phytochemical accumulation in basil plants influenced by substituting green light for partial red and/or blue light. HortScience 54:1769-1776. https://doi.org/10.21273/HORTSCI14282-19

Dou H, Niu G, Gu M, Masabni J (2020) Morphological and Physiological responses in Basil and Brassica species to different Proportions of red, blue, and green wavelengths in indoor vertical farming. J Am Soc Hortic Sci. 145:267-278. https://doi.org/10. 21273/JASHS04927-20

Dudonné S, Vitrac X, Coutière P, Woillez M, Mérillon JM (2009) Comparative study of antioxidant properties and total phenolic content of 30 plant extracts of industrial interest using DPPH, ABTS, FRAP, SOD, and ORAC assays. J Agric Food Chem 57:1768-1774. https://doi.org/10.1021/jf803011r

Fan X, Zang J, Xu Z, Guo S, Jiao X, Liu X, Gao Y (2013) Effects of different light quality on growth, chlorophyll concentration and chlorophyll biosynthesis precursors of non-heading chinese cabbage (Brassica campestris L.). Acta Physiol Plant 35:267-278. https://doi.org/10.1007/s11738-013-1304-z

Folta KM, Maruhnich SA (2007) Green light: A signal to slow down or stop. J Expt Bot 58:267-278. https://doi.org/10.1093/jxb/erm130

Gam DT, Khoi PH, Ngoc PB, Linh LK, Hung NK, Anh P, Thu NT, Hien N, Khanh TD, Ha CH (2020) LED lights promote growth and flavonoid accumulation of Anoectochilus roxburghii and linked to the enhanced expression of several related genes. Plants 9:1344. https://doi.org/10.3390/plants9101344

Girotto F, Alibardi L, Cossu R (2015) Food waste generation and industrial uses: a review. Waste Man 45:32-41. https://doi.org/ 10.1016/j.wasman.2015.06.008

Giupponi L, Ceciliani G, Leoni V, Panseri S, Pavlovic R, Lingua G, Di Filippo A, Giorgi A (2019) Quality traits of saffron produced in Italy: geographical area effect and good practices. J Appl Bot Food Qual 92:336-342

Hosseini A, Razavi BM, Hosseinzadeh H (2018) Saffron (Crocus sativus) petal as a new pharmacological target: a review. Iran J Basic Med Sci. 21:1091-1099

Hosseinzadeh H, Sadeghnia HR (2007) Protective effect of safranal on pentylenetetrazol-induced seizures in the rat: Involvement of GABAergic and opioids systems. Phytomedicine 14:256-262. https://doi.org/10.1016/j.phymed.2006.03.007

Hrazdina G, Marx GA, Hoch HC (1982) Distribution of secondary plant metabolites and their biosynthetic enzymes in pea (Pisum sativum L.) leaves - anthocyanins and flavonol glycosides. Plant Physiol 70:745-748. https://doi.org/10.1104/pp.70.3.745

Huot B, Yao J, Montgomery BL, He SY (2014) Growth-defence tradeoffs in plants: a balancing act to optimize fitness. Mol Plant 7:1267-1287. https://doi.org/10.1093/mp/ssu049

Husaini AM, Kamili AN, Wani MH, Teixeira da Silva JA, Bhat GN.: Sustainable Saffron (Crocus sativus Kashmirianus) production: technological and policy Interventions for Kashmir. In Husaini AM, (Ed) Saffron. Functional Plant Science and Biotechnology. P 116-127 (2010)

Jadouali SM, Bouzoubaâ Z, Majourhat K, Mamouni R, Gharby S, Atifi H (2017) Polyphenols content, flavonoids and antioxidant activity of petals, stamens, styles and whole flower of Crocus sativus of Taliouine. Acta Hortic. 1184:301-308. https://doi. org/10.17660/ActaHortic.2017.1184.43

Johkan M, Shoji K, Goto F, Hashida S, Yoshihara T (2010) Blue light-emitting diode light irradiation of seedlings improves seedling quality and growth after transplanting in red leaf lettuce. HortScience. 45:1809-1814. https://doi.org/10.21273/ HORTSCI.45.12.1809

Johkan M, Shoji K, Goto F, Hahida S, Yoshihara T (2012) Effect of green light wavelength and intensity on photomorphogenesis and photosynthesis in Lactuca sativa. Environ Exp Bot 75:128-133. https://doi.org/10.1016/j.envexpbot.2011.08.010

Jones MA (2018) Using light to improve commercial value. Hortic Res 5:47. https://doi.org/10.1038/s41438-018-0049-7

Jouki M, Khazaei N (2013) Effects of low-dose g-irradiation and modified atmosphere packaging on shelf life and quality characteristics of saffron (Crocus Sativus Linn) in Iran. Food Sci Biotechnol 22:1-4

Jouki M, Khazaei N, Kalbasi A, Tavakolipour H, Rajabifar S, Motamedi Sedeh F, Jouki A (2011) Study of $\gamma$ irradiation and storage time on microbial load and chemical quality of Persian Saffron. World Acad Sci, Eng Technol 53:1154-1157

Jouki M, Khazaei N, Tavakolipour H, Rajabifar S, Motamedi Sedeh F (2013) Determination of chemical characteristics of Saffron in different area of Iran. Curr Res J Biol Sci 4:71-74

Kang HM, Saltveit ME (2002) Antioxidant capacity of lettuce leaf tissue increases after wounding. J Agr Food Chem 50:75367541. https://doi.org/10.1021/jf020721c

Kim DO, Chun OK, Kim YJ, Moon HY, Lee CY (2003) Quantification of Polyphenolics and their antioxidant capacity in fresh plums. J Agr Food Chem 51:6509-6515. https://doi.org/10. 1021/jf0343074

Kopsell DA, Sams CE, Barickman TC, Morrow RC (2014) Sprouting broccoli accumulate higher concentrations of nutritionally important metabolites under narrow-band light-emitting diode lighting. J Amer Soc Hort Sci. 139:469-477. https://doi.org/10. 21273/JASHS.139.4.469

Kyriacou MC, El-Nakhel C, Pannico A, Graziani G, Soteriou GA, Giordano M, Zarrelli A, Ritieni A, De Pascale S, Rouphael Y (2019) Genotype-specific modulatory effects of select spectral bandwidths on the nutritive and phytochemical composition of microgreens. Front Plant Sci 10:1501. https://doi.org/10.3389/ fpls.2019.01501 
Kyriakoudi A, O'Callaghan YC, Galvin K, Tsimidou MZ, O’Brien NM (2015) Cellular transport and bioactivity of a major saffron apocarotenoid, picrocrocin (4-( $\beta$-D-Glucopyranosyloxy)-2,6,6trimethyl-1-cyclohexene-1-carboxaldehyde). J Agric Food Chem 63:8662-8668. https://doi.org/10.1021/acs.jafc.5b03363

Lee JS, Lee CA, Kim YH, Yun SJ (2014) Shorter wavelength blue light promotes growth of green perilla (Perilla frutescens). Intl J Agr Biol 16:1769-1776

Li Q, Kubota C (2009) Effects of supplemental light quality on growth and phytochemicals of baby leaf lettuce. Env and Exp Bot 67:5964. https://doi.org/10.1016/j.envexpbot.2009.06.011

Li J, Terzaghi W, Deng XW (2012a) Genomic basis for light control of plant development. Protein Cell 3:106-116. https://doi.org/10. 1007/s13238-012-2016-7

Li H, Tang C, Xu Z, Liu X, Han X (2012b) Effects of different light sources on the growth of non-heading chinese cabbage (Brassica campestris L.). J Agric Sci 4:262-273. https://doi.org/10.5539/ jas.v4n4p262

Li Q.: Effects of light quality on growth and phytochemical accumulation of lettuce and Salvia miltiorrhizabunge Northwest A\&F University Shanxi China PhD Dissertetion (2010)

Lobiuc A, Vasilache V, Oroian M, Stoleru T, Burducea M, Pintilie O, Zamfirache MM (2017) Blue and red led illumination improves growth and bioactive compounds contents in Acyanic and Cyanic Ocimum basilicum L. Microgreens Molecules 22:2111. https:// doi.org/10.3390/molecules22122111

Maggini R, Benvenuti S, Leoni F, Pardossi A (2018) Terracrepolo (Reichardia picroides (L.) Roth.): wild food or new horticultural crop? Sci Hortic 20:224-231. https://doi.org/10.1016/j.scienta. 2018.06.018

Maggini R, Galluzzo F, Pardossi A.: Effect of nitrogen nutrition on growth and accumulation of caffeic acid derivatives in hydroponically-grown Echinacea angustifolia DC. var angustifolia. Agrochimica 57:22-30. Scopus ID 2-s2.0-84880060555 (2013)

Manivannan A, Soundararajan P, Halimah N, Ko CH, Jeong BR (2015) Blue LED light enhances growth, phytochemical contents, and antioxidant enzyme activities of Rehmannia glutinosa cultured in vitro. Hort Environ Biotechnol 56:1769-1776. https://doi.org/ 10.1007/s13580-015-0114-1

Meng X, Xing T, Wang X (2004) The role of light in the regulation of anthocyanin accumulation in Gerbera hybrida. Plant Growth Regulat 44:1769-1776. https://doi.org/10.1007/s10725-004-4454-6

Menghini L, Leporini L, Vecchiotti G, Locatelli M, Carradori S, Ferrante C, Zengin G, Recinella L, Chiavaroli A, Leone S, Brunetti L, Orlando G (2018) Crocus sativus L. stigmas and byproducts: qualitative fingerprint, antioxidant potentials and enzyme inhibitory activities. Food Res Int 109:91-98. https://doi.org/10.1016/j. foodres.2018.04.028

Moratalla-Lopez N, Bagur JM, Lorenzo C, Martinez-Navarro ME, Rosario Salinas M, Alonso GL (2019) Bioactivity and Bioavailability of the major metabolites of Crocus sativus L flower (review). Molecules. 24:2827. https://doi.org/10.3390/molecules2 4152827

Mosadegh H, Trivellini A, Ferrante A, Lucchesini M, Vernieri P, Mensuali A (2018) Applications of UV-B lighting to enhance phenolic accumulation of sweet basil. Sci Hortic 229:107-116. https://doi. org/10.1016/j.scienta.2017.10.043

Mosadegh H, Trivellini A, Maggini R, Ferrante A, Incrocci L, Mensuali A (2021) In-vivo in-vitro screening of ocimum basilicum $L$ ecotypes with differential UV-B radiation sensitivity. Horticulturae 7:101. https://doi.org/10.3390/horticulturae7050101

OEC.: Saffron trade. Retrieved 10th May 2019, from https://atlas.media mit.edu/en/profile/hs92/091020. (2019)

Olle M, Virsile A (2013) The effects of light emitting diode on greenhouse plant growth and quality. Agric Food Sci. 22:223-234. https://doi.org/10.23986/afsci.7897
Ouzounis T, Heuvelink E, Ji Y, Schouten HJ, Visser RGF, Marcelis LFM (2016) Blue and red LED lighting effects on plant biomass, stomatal conductance, and metabolite content in nine tomato genotypes. Acta Horticulturae. 1134:251-258. https://doi.org/ 10.17660/ActaHortic.2016.1134.34

Paradiso R, Proietti S (2021) light quality manipulation to control plant growth and Photomorphogenesis in greenhouse horticulture: the state of the art and the opportunities of modern led systems. J Plant Growth Regul 1435:8107. https://doi.org/10.1007/ s00344-021-10337-y

Pennisi G, Blasioli S, Cellini A, Maia L, Crepaldi A, Braschi I, Spinelli F, Nicola S, Fernández JA, Stanghellini C (2019) Unravelling the role of red:blue LED lights on resource use efficiency and nutritional properties of indoor grown sweet basil. Frontiers Plant Sci 10:305. https://doi.org/10.3389/fpls.2019.00305

Radovanović B, Radovanović A, Souquet J (2010) Phenolic profile and free radical-scavenging activity of Cabernet Sauvignon wines of different geographical origins from the Balkan region. J Sci Food Agric 90:2455-2461. https://doi.org/10.1002/jsfa.4106

Riahi-Chebbi I, Souid S, Othman H, Haoues M, Karoui H, Morel A, Srairi-Abid N, Essafi M, Essafi-Benkhadir K (2019) The Phenolic compound Kaempferol overcomes 5-fluorouracil resistance in human resistant LS174 colon cancer cells. Sci Rep 9:195. https:// doi.org/10.1038/s41598-018-36808-Z

Serrano-Díaz J, Sánchez AM, Maggi L, Martínez-Tomé M, GarcíaDiz L, Murcia MA, Alonso GL (2012) Increasing the applications of Crocus sativus flowers as natural antioxidants. J Food Sci 77:1162-1168. https://doi.org/10.1111/j.1750-3841.2012. 02926.x

Serrano-Díaz J, Sánchez AM, Martínez-Tomé M, Winterhalter P, Alonso GL (2013) A contribution to nutritional studies on Crocus sativus flowers and their value as food. J Food Compos 31:101-108. https://doi.org/10.1016/j.jfca.2013.03.009

Serrano-Díaz J, Estevan C, Sogorb MÁ, Carmona M, Alonso GL, Vilanova E (2014) Cytotoxic effect against 3 T3 fibroblasts cells of saffron floral bio-residues extracts. Food Chem 147:55-59. https://doi.org/10.1016/j.foodchem.2013.09.130

Sharma A, Shahzad B, Rehman A, Bhardwaj R, Landi M, Zheng B (2019) Response of Phenylpropanoid pathway and the Role of Polyphenols in plants under abiotic stress. Molecules 24:2452

Shiga T, Shoji K, Shimada H, Hashida SN, Goto F, Yoshihara T (2009) Effect of light quality on rosmarinic acid content and antioxidant activity of sweet basil, Ocimum basilicum L. Plant Biotechnol 26:1769-1776. https://doi.org/10.5511/plantbiote chnology.26.255

Singh D, Basu C, Meinhardt-Wollweber M, Roth B (2015) LEDs for energy efficient greenhouse lighting. Ren Sustain Ener Rev 49:139-147. https://doi.org/10.1016/j.rser.2015.04.117

Stelluti S, Caser M, Demasi S, Scariot V (2021) Sustainable processing of Floral bio-residues of Saffron (Crocus sativus L.) for valuable biorefinery products. Plants. 10:523. https://doi.org/10.3390/plant s 10030523

Stutte GW, Edney S, Skerritt T (2009) Photoregulation of bioprotectant content of red leaf lettuce with light-emitting diodes. HortScience. 44:79-82. https://doi.org/10.21273/HORTSCI.44.1.79

Talaei A, Hassanpour Moghadam M, SajadiTabassi SA, Mohajeri SA (2015) Crocin, the main active saffron constituent, as an adjunctive treatment in major depressive disorder: a randomized, double-blind, placebo controlled, pilot clinical trial. J Affect Disord 174:51-56. https://doi.org/10.1016/j.jad.2014.11.035

Talbott LD, Hammad JW, Harn LC, Nguyen VH, Patel J, Zeiger E (2006) Reversal by green light of blue light-stimulated stomatal opening in intact, attached leaves of arabidopsis operates only in the potassium-dependent, morning phase of movement. Plant Cell Physiol 47:267-278. https://doi.org/10.1093/pcp/pci249 
Tattini M, Remorini D, Pinelli P, Agati G, Saracini E, Traversi ML, Massai R (2006) Morpho-anatomical, physiological and biochemical adjustments in response to root zone salinity stress and high solar radiation in two Mediterranean evergreen shrubs, $M y r$ tus communis and Pistacia lentiscus. New Phytol 170:779-794. https://doi.org/10.1111/j.1469-8137.2006.01723.x

Taulavuori K, Julkunen-Tiitto R, Hyöky V, Taulavuori E (2013) Blue mood for superfood. Nat Product Commun. 8:791-794

Taulavuori K, Hyöky V, Oksanen J, Taulavuori E, Iulkunen-Tiitto R (2016) Species specific differences in synthesis of flavonoids and phenolic acids under increasing periods of enhanced blue light. Env Exp Bot 121:145-150. https://doi.org/10.1016/j.envexpbot. 2015.04.002

Taulavuori K, Pyysalo A, Taulavuori E, Julkunen-Tiitto R (2018) Responses of phenolic acid and flavonoid synthesis to blue and blue-violet light depends on plant species. Environ Exp Bot 150:183-187. https://doi.org/10.1016/j.envexpbot.2018.03.016

Trivellini A, Lucchesini M, Maggini R, Mosadegh H, Villamarin TSS, Vernieri P, Mensuali-Sodi A, Pardossi A (2016) Lamiaceae phenols as multifaceted compounds: bioactivity, industrial prospects and role of positive-stress. Ind Crops Prod 83:241-254. https:// doi.org/10.1016/j.indcrop.2015.12.039

Varzakas T, Zakynthinos G, Verpoort F (2016) Plant food residues as a source of nutraceuticals and functional foods. Foods 10:88. https://doi.org/10.3390/foods5040088
Wang Y, Folta KM (2013) Contributions of green light to plant growth and development. Amer J Bot 100:267-278. https://doi.org/10. 3732/ajb.1200354

Ward JM, Cufr CM, Denzel MA, Neff MM (2005) The dof transcription factor OBP3 modulates Phytochrome and cryptochrome signaling in arabidopsis. Plant Cell 17:475-485. https://doi.org/10. $1105 /$ tpc. 104.027722

Weller JL, Kendrick RE (2008) Photomorphogenesis and photoperiodism in plants. In: Björn LO (ed) Photobiology: the science of light and life. Springer, New York, pp 299-321

Whitelam GC, Halliday KJ.: Light and Plant Development. Annual Plant Reviews 30 (Blackwell Publishing, UK, 2007) (2007)

Wollaeger HM, Runkle ES (2014) Growth of impatiens, petunia, salvia, and tomato seedlings under blue, green, and red light-emitting diodes. HortScience. 49:734-740. https://doi.org/10.21273/ HORTSCI.49.6.734

Zhang T, Folta KM (2012) Green light signaling and adaptive response. Plant Signal Behav 7:267-278. https://doi.org/10.4161/psb.7.1. 18635

Publisher's Note Springer Nature remains neutral with regard to jurisdictional claims in published maps and institutional affiliations. 